\title{
LIGHT TRANSMISSION THROUGH POSTS TO SIMULATED REGIONAL ROOT CANAL USING DIFFERENT CURING SOURCES
}

\author{
Mohamed Atif Mohamed Alkholy* and Mohamed Farag Ayad**
}

\begin{abstract}
Statement of problem: Light-activated luting agents have become an indispensable material for clinical dental use. However, it remains debatable as to which level, the light curing unit provides sufficient intensity of light to achieve polymerization.

Purpose: The purpose of this study was to assess quantitatively the light intensity transmitted from three different light sources through translucent glass fiber posts with sequential cuts at depths of $15 \mathrm{~mm}, 10 \mathrm{~mm}, 5.0 \mathrm{~mm}$

Materials and Methods: A 15 x $30 \mathrm{~mm}$ hollow Teflon ring was used. 60 specimens were prepared and assigned randomly into three groups ( $\mathrm{n}=20$ per each) according to the curing source. Within each group, 15 specimens were used for the experimental and 5 for the control group. For the experimental ones, a self-cure acrylic resin with black pigment was poured into the ring. A translucent glass fiber post was placed in the center of each ring and held in position till complete polymerization was occurred. For the control groups, the black resin blocks were filled with a lubricated dowel for its later removal. Therefore, the resin blocks with internal hollow orifices were obtained without the dowel. After preparing the blocks, readings for the passage of light will be made at the apical, middle , and cervical third level, involving dowel lengths of $15,10,5 \mathrm{~mm}$ respectively. A 40-second light exposure was used for each specimen and curing unit combination.The output of light intensity was recorded. Mean light intensities were analyzed with 2-way ANOVA test followed by Kruskal-Wallis tests at $\alpha=0.05$.
\end{abstract}

Results: Two-way ANOVA results of light intensities for the experimental and control groups demonstrated significant differences between the light curing units $(\mathrm{P}<0.001)$ and the root level $(\mathrm{P}<0.001)$. Moreover, their interaction was also significantly different $(\mathrm{P}<0.001)$. For the experimental groups, Kruskal Wallis test revealed the highest quantity of light intensity was recorded for the high power LED curing unit at the cervical level of the root canal. For the control groups, the highest quantity of light intensity was displayed for the HPLED curing unit at the cervical level of the root canal.

Conclusions: The quantity of the light intensity transmitted from three different light sources are significant different through translucent glass fiber posts with sequential cuts at depths of $15 \mathrm{~mm}, 10 \mathrm{~mm}, 5.0 \mathrm{~mm}$.

BDS - 2010,

**Professor of Fixed Prosthodontic, Faculty of Dentistry, Tanta University 


\section{INTRODUCTION}

The use of visible light to cure dental materials has expanded over recent years to incorporate a vast array of products including cementation and bonding of fiber reinforced composite dowels. Successful use of these products depends directly on correct functioning of light curing unit. Three essential components are required for adequate polymerization: sufficient radiant intensity, correct wavelength of the visible light and ample curing time. ${ }^{1}$ Other factors also influence the depth, and therefore the adequacy of polymerization. These include the type of composite resin, shade, translucency, temperature of composite material, thickness of the increments, distance of the light tip from the surface of the material, curing time and post-irradiation time. ${ }^{2}$

As the curing light ages, the light output diminishes due to deterioration of the components. In addition, numerous factors are capable of interfering with efficient function of the light curing unit. Some of these comprise fluctuations in the line voltage, condition of the bulb and filter, contamination of the light guide or image to the fiber-optic bundle, reduced light output after repeated sterilising,and heat build-up within the unit.

\section{Evolution of Light Curing Units:}

Light is a type of electromagnetic radiation with a wavelength range between 400 and $700 \mathrm{~nm}$. The key characteristic of the radiation is that it is transformed by the human brain into vision. Light is characterized in terms of its wavelength, which is related to color; its power (amount of radiation), and its intensity (power per area unit of surface). When radiation in the form of waves collides with particles in its path, it undergoes absorption, reflection, and refraction; these phenomena prompt a progressive drop in power or intensity as the radiation advances, either in the air or within a material. Thus, the amount of radiation reaching a given point in the material will depend on several factors ${ }^{4}$
- Lamp output intensity. This, in turn, is governed by lamp power rating and light-guide diameter.

- Exposure time. Since lamp energy output is the product of intensity multiplied by exposure time, The same energy can be consumed at high or low intensity, as the exposure time is adjusted to maximize energy efficiency ${ }^{5}$.

- Distance from light source to material. As a part of the emitted light is absorbed by the air through which it passes, thus decreasing the intensity reaching the target surface.

- Curing depth light is gradually absorbed within the working material, so that for any given target depth, the amount of energy required will be equal to the product of the intensity reaching that point and the duration of exposure.

- Presence of elements between light source and target material. The amount of light absorbed by intervening elements will vary according to the thickness and optical behavior of elements concerned. Because enamel is very transparent, it allows the passage of a great deal of light; so polymerization can readily be affected through the enamel layer. Dentin is considerably less transparent, allowing virtually no light to pass through at all. The passage of light through bands and performed crown is similarly governed by transparency and thickness. Thus, when curing through dental structures, the best results are obtained by reducing intensity rather than by controlling the direction of polymerization shrinkage. Of all these factors, light intensity seems to be the most important.

A range of curing units is currently marketed, differing in technology and thus in the working technique to be used. ${ }^{6}$

\subsection{Quartz-halogen light curing unit.}

Quartz-tungsten halogen (QTH) light curing units (LCUs) are routinely used to irradiate resin- 
based composites, bonding systems, bases and liners, luting agents and some interim restorative materials dental clinics by producing filtered blue light by thermonic emission Halogen bulbs have a short working life of about 100 hours, the dielectric pass-band filter, the reflector, and the bulb degrade over time due to the high operating temperatures produced during function. Damage to the fiber optic bundle due to poor handling and repeated sterilization can all lead to a reduction in the irradiance over time. ${ }^{7}$

\subsection{LED light curing unit}

Technical advancements in light-emitting diode (LED) light curing units have occurred rapidly science their initial introduction. The first generation units consisted of an array of relatively low-powered chips offering a comparative low output, and poor curing performance compared with conventional quartz- tungsten-halogen (QTH) lights. Generally, these lights had to be used for longer exposure times to provide similar curing to that of QTH lights, but resulted in less temperature generation in the target. The 1st-generation LED lights generally were low in intensity and did not cure materials completely. The diodes were designed to activate CQ (camphorquinone) initiator around $460 \mathrm{~nm}$. However, alternative photo-initiators used in bleach shades and incisal (translucent) shades of composites and in sealants and bonding agents are not activated by these "blue-light" units 8 .

Second generation models demonstrate better performance, using a single chip of much higher surface area that emits only one color range of greatly increased output power. Many second generation LED lights are able to provide equivalent curing performance to that of conventional QTH sources using similar exposure times, but may induce temperatures higher than those from a QTH source. The 2nd-generation LED light-curing units (Bluephase, Elipar Freelight 2, L.E. Demetron1, radii, Allegro, Smart Lite iQ, the CURE) have a single, high-powered diode with multiple emission areas. These units have a large surface area of emission and high-energy output.

The third generation LED units are characterized by incorporating the same blue chip as the second generation products, but include one or more low-powered chips that emit a second frequency in the violet spectral range. Target temperatures are directly correlated to power density levels and differences in emission spectra, despite the absence of infrared energy in any of the curing lights' spectra. ${ }^{9}$ With the increased output of these chips, the manufacturer must be concerned with internal heat generation in the chip itself because, if not controlled, the heat will result in irreversible damage to the internal electrical connections within the chip wafer itself, resulting in a permanently nonfunctioning unit ${ }^{9}$.

The 3rd-generation LED light-curing units have two or more diode frequencies and emit light in different ranges to activate CQ and alternative photo-initiators.

To help minimize this effect, manufacturers use a variety of mechanisms to remove internal heat from the chip. Both convective (fans) and conductive (devices used to directly draw heat away: heat-sinks) designs are incorporated into second generation lights. Also, thermostatic control for the chip is provided to limit the level to which heat can rise. Until the chip cools to a predetermined temperature, the unit remains inoperable ${ }^{10}$.

\subsection{Argon Laser and plasma arc light curing unit}

In contrast; Argon laser sources emit light at a few distinct frequencies within the desired region, thus completely eliminating the need for filtering undesired wavelengths as compared to conventional light sources. However, a plasma arc light source does not emit distinct frequencies but continuous frequency bands. However, these bands are 
much narrower than those of incandescent lights. Therefore, less radiation of undesired frequencies must be filtered. The plasma curing light Apollo 95 E (DMDS, Marburg, Germany) emits light at frequencies between $440 \mathrm{~nm}$ and $500 \mathrm{~nm}$, with peaks at $470 \mathrm{~nm}$ and $485 \mathrm{~nm}$ and an intensity of $1320 \mathrm{~mW} /$ $\mathrm{cm}^{2}$. Due to the high intensity, the manufacturer claims that $1 \mathrm{~s}$ to $3 \mathrm{~s}$ of plasma irradiation cures many resin composites to a hardness similar to that achieved after 40 seconds with conventional curing lights.

\section{Radiometer as a Method to Evaluate Light Intensit}

Manufacturers now market curing radiometers to be used periodically to measure light output. It is claimed that a direct relationship exists between intensity readings and depth of cure; however, conflicting opinions of their usefulness have been reported. Hansen and Asmussen ${ }^{11}$ have reported that three different dental radiometers were unable to rank 20 curing units by the depth of cure and concluded that they were not fully reliable. However, Peutzfeldt ${ }^{12}$ found a significant linear correlation between a light intensity tester and the degree of conversion of a light-curing resin. A linear decrement in measured intensity value has been reported in two hand radiometers for a given amount of decrease in light source intensity value. A spectroradiometer and a commercial curing radiometer were used to measure the light intensity of five light-curing units. They were found to correlate at wave-lengths of $450-500 \mathrm{~nm} .{ }^{13}$ When light intensity readings assessed by dental radiometers were normalized with regard to a standardized light sensing device aperture of $4 \mathrm{~mm}$ diameter, a linear relationship existed between depth of cure and the logarithm of the intensity of the light. Of 209 curing lights evaluated from private dental offices, $29.7 \%$ had a light intensity of less than $200 \mathrm{~mW} / \mathrm{cm}^{2}$ which is inadequate to provide the required degree of polymerization, $15.8 \%$ had a light intensity in the range of 200-300 $\mathrm{mW} / \mathrm{cm}^{2}$ necessitating increased irradiation times according to the manufacturer's recommendations. ${ }^{14}$ However, no attempt was made to relate the light intensity to actual clinical performance by measuring depth of cure, or to comment on the manufacturer's recommendations. According to the manufacturer of the curing and heat radiometers, two independent criteria dictate whether to repair or replace the curing light: a reading of $<200 \mathrm{~mW} / \mathrm{cm}^{2}$ by the curing radiometer or a reading of $>50 \mathrm{~mW} / \mathrm{cm}^{2}$ by the heat radiometer.

\section{Evolution of Endodontic Posts}

\subsection{Metal dowels}

Dowels can generally be divided into two types, depending on how retention is achieved. One type is the active posts which derive their primary retention directly from the root dentin by the use of threads. The second type is the passive posts which gain their retention by passively seating in close proximity to the post-hole walls, and rely primarily on the luting cement for their retention ${ }^{15}$.

\subsection{Metal-free dowels}

Metal-free post systems can be broadly divided into composite (epoxy-resin fiber) and ceramic post systems. Carbon fiber materials were developed and the first generation of non-metal postsComposipost- was made commercially available in Europe in 1990. This system was dark in colour and hence was not ideally compatible for use with all ceramic restorations. This system was dark in colour and hence was not ideally compatible for use with all ceramic restorations. To overcome this, manufacturers have substituted the carbon fibers with glass fibers, hence the evolution of the glass/ silica/quartz fiber post. The esthetic post was the first generation of silica fiber post, where by the post retained a central core of carbon fiber bundles but had a periphery of quartz fibers arranged longitudinally. ${ }^{16}$ 
The next generation was the, Esthetiplus post, which has been developed in 1995 and composed entirely of quartz fibers in a resin matrix. Another system the, Light post, which was composed of translucent quartz fibers which permitting light transmission and thus facilitating polymerization of the adhesive luting cement within the canal along the entire length of the post. Currently, different types of fiber resin post systems are commercially available. When many studies found that Zirconia posts also have poor resin-bonding capabilities to dentin after dynamic loading and thermocycling due to the rigidity of the dowel. When the mechanical properties of zirconia posts were evaluated, it was reported that they are very stiff and strong, with no plastic behavior. When a cyclic loading test performed in a wet environment, Fakih et a ${ }^{17}$ found that the survival rate of zirconia posts compared to fiber posts was significantly lower. Several authors indicated that many commonly used posts exhibit higher fracture resistance than zirconia posts. In addition, if they fractured, the retained segment may not be retrievable.

Glass fiber supported resin post systems were introduced in 1993 as a result of research focused in the development of biocompatible endodontic post capable of optimally satisfying functional and esthetic concerns. The glass fiber reinforced post is an endodontic post with numerous clinical advantages. The posts are composed of unidirectional glass fibers embedded in a resin matrix that strengthens the post without compromising the modulus of elasticity, while more recently fiber posts showed to represent a valid alternative. In longitudinal clinical studies, the very low number of failures has been underlined $^{18}$.

\section{Luting Cement}

However, the performance of an adhesive technique in root canals can be compromised owing to the characteristics of the root dentine. In particular, an adhesive technique using a light- cured resin material can be less than ideal, due to the significantly reduced light intensity in a root canal as a result of light scattering within the resin cement and shadowing produced by both the tooth structure and the post. Therefore, dual-cured resin cements and adhesive systems combining self-cured and light-cured capabilities have been employed to bond fiber posts in a root canal. Nonetheless, although the two initiation systems allow use with limited light penetration, some dual cured materials have still been reported to be primarily dependent on light-activation. ${ }^{19}$

Sufficient light transmission through the posts is still mandatory, even when dual-cured resin cements are used for post fixation. Unlike opaque posts, translucent glass or quartz fiber posts seem to transmit light to the internal area of a root canal and induce polymerization of light cured or dualcured materials, resulting in an increased cure depth. However, even translucent fiber posts can limit light transmission to values lower than $40 \%$ of incident light and may not guarantee an adequate degree of conversion of the resin materials. Several studies have already presented the degree of conversion values of resin cements light-cured through fiber posts in a root canal. Yet, most of these studies employed micro hardness tests to evaluate the degree of conversion for resin cements cured through light-transmittable fiber posts ${ }^{20}$.

Translucent fiber posts should allow light to be transmitted into the root canal. This would increase the conversion degree of dual-cured composite resins with a consequent improvement of their mechanical properties such as modulus of elasticity and hardness. However, the ability to transmit light through the post has still to be determined. The exclusive use of dual-cured or selfcuring composites to lute fiber posts is therefore recommended. However, mechanical tests carried out in a pilot study showed no remarkable difference between the use of light-curing and dual-cured 
composite resin in the cementation of translucent. Nowadays, translucent fiber posts in conjunction with dual cured resin cement are preferred. ${ }^{21}$

The property of translucency of light transmitting posts proves favorable for luting purposes, as the transmission of light through the post, into the depths of the root canal, allows adequate polymerization of the dual cure resin cement. However, light intensity declines rapidly as the distance from the light source increases, because of light scattering within the resin cement and shadowing produced by both the tooth structure and post. Therefore, light intensity may be insufficient for the complete curing of resin cement at the apical end, which might lead to inferior physical and biological properties ${ }^{22}$.

\section{5- Evaluation of Degree of Polymerization of Dual Cure Luting Cement}

Sonali Taneja, $2013^{23}$ evaluate the influence of light transmission through different esthetic posts on the degree of polymerization of a dual cure resin cement after its sectioning into three equal parts of $5 \mathrm{~mm}$ each (coronal, middle, apical). The cured cement was pulverized and the powdered sample was mixed with potassium bromide powder in a ratio of 1:100. The sample was put into a hydraulic press model, to make pellets of $13 \mathrm{~mm}$ diameter under a seven-ton hydraulic pressure. Spectra of the cured and uncured resin cements were obtained by using Fourier transform infrared( FTIR). The degree of conversion\% (DC) was calculated .

Several other studies have already presented the degree of conversion values of resin cements light-cured through fiber posts in a root canal. Yet, most of these studies employed micro-hardness tests to evaluate the degree of conversion for resin cements cured through light-transmittable fiber posts, rather than Fourier transform infrared (FTIR) spectroscopy or Raman spectroscopy, which are more accurate methods for evaluating the value. For example, when using a Knoop hardness (KH) test, they observed that the $\mathrm{KH}$ values for a resin composite decreased with the depth in a root canal restored with a fiber post. Meanwhile, Faria e Salive et al. $2007^{24}$ evaluated the degree of conversion of a dual-cured resin cement used to lute fiber posts with different translucencies. In this study, which used polyvinylsiloxane molds to simulate root canals and Raman spectroscopy, it was found that the degree of conversion values were dependent on the depth of the root canal and type of post. However, there have been relatively few studies on the degree of conversion of resin cements light-cured within the root canal.

\section{AIM OF THE STUDY}

The purpose of this in vitro study was to assess quantitatively the light intensity transmitted from three different light sources (Quartz Tungsten Halogen, Conventional light emitting diodes, High Power light emitting diodes) through translucent glass fiber posts with sequential cuts at depths of $15 \mathrm{~mm}$ (apical), $10 \mathrm{~mm}$ (middle), $5.0 \mathrm{~mm}$ (cervical)

\section{MATERIALS AND METHODS}

The study protocol was approved by the Institutional Research Committee of Tanta University, Tanta, Egypt. This investigation involved the use of three light curing units (LCUs), one translucent glass fiber post and the light intensity was measured by digital radiometer at sequential cuts at depths of $15 \mathrm{~mm}$ (apical), $10 \mathrm{~mm}$ (middle), and $5.0 \mathrm{~mm}$ (cervical). The three LCUs, which had different light sources, are listed in Table 1

A 15 x $30 \mathrm{~mm}$ hollow Teflon ring with 2 central orifices in opposing faces to guide each post into the long axis of the ring was used. Sixty specimens were prepared and assigned randomly into three groups ( $n=20$ per each group) according to the curing source. Within each group, fifteen specimens were used for the experimental and five specimens for the control. 
TABLE (1) LCUs used in the study

\begin{tabular}{|c|c|c|c|}
\hline $\mathrm{LCU}$ & Manufacture & Light source $^{\mathrm{a}}$ & Tip diameter-mm \\
\hline $\begin{array}{l}\mathrm{COXO} \\
(\mathrm{QTH})\end{array}$ & $\begin{array}{l}\text { FashionCoxo medical instrument Co., } \\
\text { Guangdong, Province, China }\end{array}$ & $\begin{array}{l}\text { Quartz-tungsten halogen bulb }(75 \mathrm{~W} \text {, } \\
8.5 \times 9.5 \mathrm{~mm} \text { oval) with reflector }(\varnothing 31 \mathrm{~mm})\end{array}$ & 8 \\
\hline $\begin{array}{l}\text { Blue-LED } \\
\text { (LED) }\end{array}$ & $\begin{array}{l}\text { Monitex Industrial Co., } \\
\text { LTD, San-Chong, Taiwan }\end{array}$ & $(5 \mathrm{~W}, \varnothing 6 \mathrm{~mm})$ & 8 \\
\hline $\begin{array}{c}\text { High power } \\
\text { Bluephase (LED) }\end{array}$ & $\begin{array}{l}\text { Ivoclar-Vivadent, } \\
\text { Amherst, NY USA }\end{array}$ & $\begin{array}{c}\text { Bulb }(300 \mathrm{~W}, \varnothing 8 \mathrm{~mm}) \\
\text { with reflector }(\varnothing 74 \mathrm{~mm})\end{array}$ & 8 \\
\hline
\end{tabular}

a Light source as provided by the manufacturers. QTH, Quartz-halogen light; LED, light-emitting diode; High power LED, 3rd-generation LED. The LCUs used in this study were used for the first time and their light bulbs were brand new.

\section{Sample preparation}

For the experimental groups $(\mathrm{n}=15)$, a selfcure acrylic resin (Shnghai New Century Dental Materials Co., LTD, Shanghai, China) with black pigment (Glory, Kuria Mal \& Sons, Delhi, India) was poured into the ring using a dental vibrator (E-Z Flo Vibrator, Kerr Manufacturing Co., Romulus, Mich.) to eliminate voids . A translucent glass fiber post was placed in the center of each ring guided by the 2 central orifices in opposing faces of the ring and held in position till complete polymerization was occurred. A dental surveyor (J.M. Ney Co, Bloomfield, CT) was also used to align the dowel perpendicular to the base of the acrylic mold. (Fig. 1) To standardize the dowels length at $15 \mathrm{~mm}$, all dowels were cut to leave $2 \mathrm{~mm}$ protruding from the surface of each resin block.

For the control groups $(n=5)$, the black resin blocks were filled with a lubricated dowel for its later removal. Therefore, the resin blocks with internal hollow orifices were obtained without the dowel .

A metallic apparatus that maintained the relation between the light source, the specimen, and the radiometer was used. This apparatus was custom made to precisely hold the block for each measurement depth. (Fig. 2).

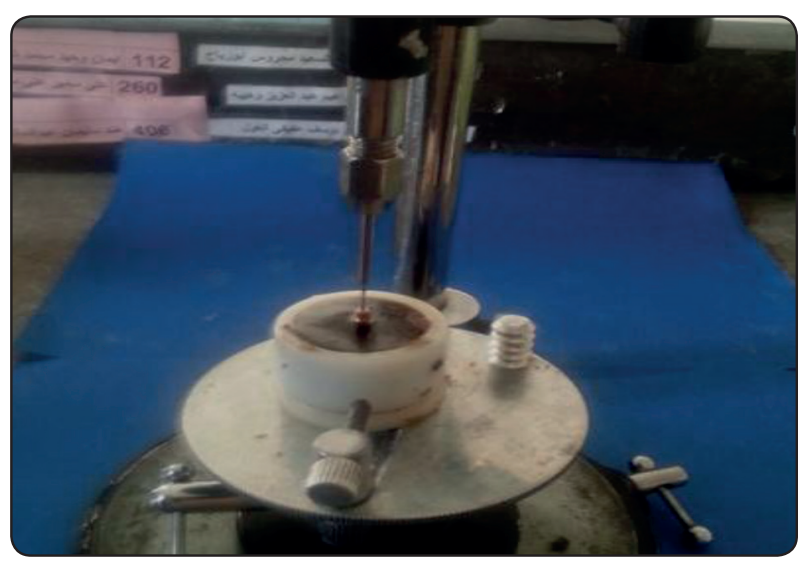

Fig. (1) The dowel aligned perpendicular to the base of the acrylic mold by dental surveyor

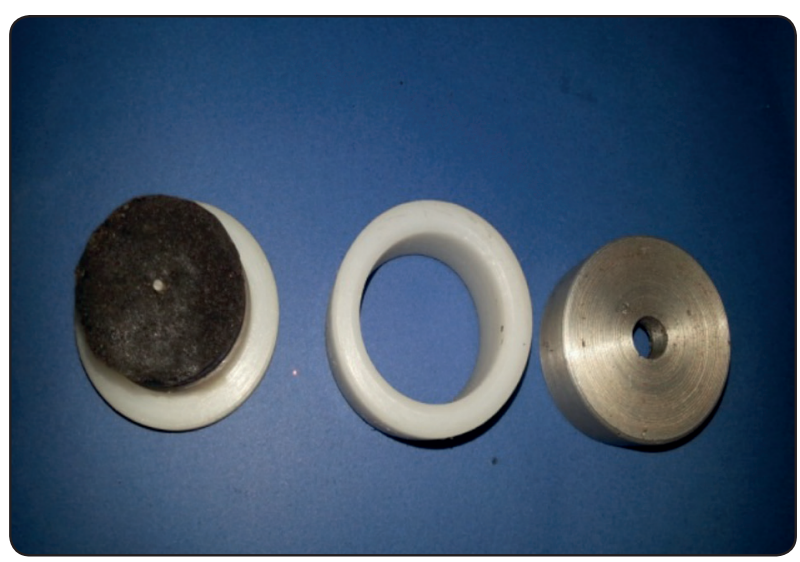

Fig (2) A black acrylic cylinder with the fiber post in Teflon rings and a metal device 


\section{Light intensity measurements}

After preparing the blocks, readings for the passage of light will be made at the apical third level, middle third level, and cervical third level, involving dowel lengths of $15,10,5 \mathrm{~mm}$ respectively.

To obtain readings, the specimens were progressively cut in a sawing machine, complying with manufacturer's cooling specifications and removing material from the apical surface of the blocks

A 40-second light exposure was used for each specimen and curing unit combination and the output of light intensity was recorded. The tip of each light curing unit was held at the top of each dowel. Three measurements were recorded for each depth assessed and averaged using a radiometer (Apoza, Chung, Taipei City, Taiwan) according to the manufacture's instructions. Due to analogue readings, result were interpolated and recorded in steps of $25 \mathrm{~mW} / \mathrm{cm}^{-2}$ (i.e. $25-50,50-75,75-100$ $\mathrm{mW} / \mathrm{cm}^{-2}$ ) etc .

To standardize the light intensity, the light curing source was preheated with five 40 -second cycles. Between each measurement, the light curing source was left at rest for 1-minute, which is the time necessary for the cooling fan to automatically turn off. Moreover, the power intensity was measured twice each day during the experiment using the radiometer. A light tip with $8-\mathrm{mm}$ diameter was used for each light curing units. Fig. 3 .

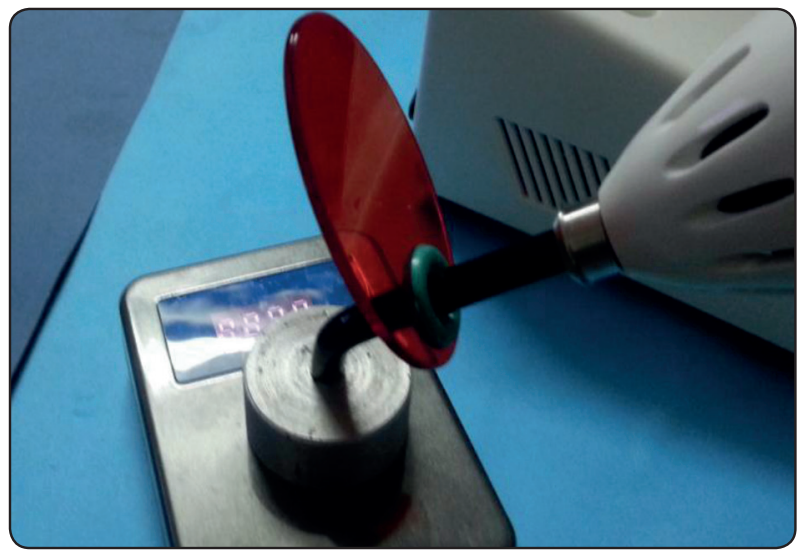

Fig. (3) Measuring Light intensity of light cure devices by radiometer
Otherwise, to calculate the light intensity to three areas, the values obtained in $\mathrm{mW} / \mathrm{cm}^{2}$ will be converted to $\mathrm{W} / \mathrm{mm}^{2}$ by applying the formula $\mathrm{mWx} 4 / \pi \mathrm{d} 2$.

\section{Statistical analysis}

Mean values for each group were calculated, and differences between the groups were tested for statistical significance by use of 2-way analysis of variance (ANOVA) and Kruskal-Wallis tests at $\alpha=0.05$

\section{RESULTS}

Two-way ANOVA results of light intensities for the experimental and control groups in Tables 2 (experimental groups) and 3 (control groups) demonstrated significant differences between the light curing units $(\mathrm{P}<0.001)$ and the root level $(\mathrm{P}<0.001)$. Moreover, their interaction was also significantly different $(\mathrm{P}<0.001)$.

TABLE (2) Two-way repeated measures ANOVA for experimental groups

\begin{tabular}{|c|c|c|c|c|}
\hline Source & Df & MS & F & $P$ \\
\hline Light curing units & 2 & 2.4 & 32.9 & $<0.001$ \\
\hline Root level & 2 & 10.1 & 139.1 & $<0.001$ \\
\hline $\begin{array}{c}\text { Light curing units x } \\
\text { root level }\end{array}$ & 4 & 1.2 & 17.1 & $<0.001$ \\
\hline
\end{tabular}

TABLE (3) Two-way repeated measures ANOVA for control groups

\begin{tabular}{|c|c|c|c|c|}
\hline Source & $D f$ & MS & F & $P$ \\
\hline Light curing units & 2 & 10.5 & 34.1 & $<0.001$ \\
\hline Root level & 2 & 110.2 & 358.5 & $<0.001$ \\
\hline $\begin{array}{c}\text { Light curing units } \\
\text { x root level }\end{array}$ & 4 & 4.3 & 13.9 & $<0.001$ \\
\hline
\end{tabular}


TABLE (4) Light tansmitted for experimental and control groups according to root canal level (mean $\left.\pm \mathrm{SD} \mathrm{W} / \mathrm{mm}^{2}, \mathrm{n}=5\right)$

\begin{tabular}{|l|c|c|c|}
\hline Root canal level & \multicolumn{3}{|c|}{ Light curing unit } \\
\hline & QTH$^{1}$ & LED $^{2}$ & High power LED \\
\hline Experimental groups & \\
\hline Cervical - 5mm & $0.7 \pm 0.2^{\mathrm{d}}$ & $1.5 \pm 0.7^{\mathrm{e}}$ & $2.6 \pm 0.3^{\mathrm{f}}$ \\
\hline Middle - 10mm & $0.4 \pm 0.1^{\mathrm{g}}$ & $0.6 \pm 0.1^{\mathrm{h}}$ & $0.9 \pm 1.7^{\mathrm{i}}$ \\
\hline Apical - 15mm & $0.0 \pm 0.0^{\mathrm{j}}$ & $0.0 \pm 0.0^{\mathrm{j}}$ & $0.0 \pm 0.0^{\mathrm{j}}$ \\
\hline Control group & & & \\
\hline Cervical - $5 \mathrm{~mm}$ & $4.1 \pm 0.3^{\mathrm{k}}$ & $7.3 \pm 0.8^{\mathrm{l}}$ & $6.8 \pm 1.2^{\mathrm{l}}$ \\
\hline Middle - $10 \mathrm{~mm}$ & $1.8 \pm 0.4^{\mathrm{m}}$ & $1.7 \pm 0.4^{\mathrm{m}}$ & $3.2 \pm 0.9^{\mathrm{n}}$ \\
\hline Apical - $15 \mathrm{~mm}$ & $0.4 \pm 0.2^{\circ}$ & $0.9 \pm 0.2^{\mathrm{p}}$ & $1.1 \pm 0.2^{\mathrm{p}}$ \\
\hline
\end{tabular}

Different superscript numbers indicate significant differences between the levels of the dowel system $(p<0.001)$. Different lowercase letters represent significant differences between the root canal level and the root canal level*light curing unit within each group $(\mathrm{p}<0.001)$.

Table 4 displays the means and standard deviations of the quantities of light transmitted to different depths for the experimental and control groups. For the experimental groups, Kruskal Wallis test revealed the highest quantity of light intensity was recorded for the high power LED curing unit at the cervical level of the root canal. For the control groups, the highest quantity of light intensity was displayed for the LED curing unit at the cervical level of the root canal.

Comparing the light curing units, the high power LED light curing unit, produced the highest light intensity regardless to the root canal level which was significantly different form all other light curing units $(\mathrm{P}<0.001)$. The lowest reading was recorded with QTH light curing unit. The mean light intensity for LED light curing unit was intermediate.

\section{DISCUSSION}

The current research was based on the study of three widely used light curing units and it is probable that the conclusions will also apply to a wider range of units. The results of the study reject the null hypothesis that the translucent post may be able to transmit light to depths sufficient to cure resin cements. Previous studies have reported that commercial dental LCUs with different light sources, i.e., quartz-tungsten halogen, plasmaarc light bulbs, and light emitting diode (LED), provide significantly uneven and inhomogeneous light intensity from the light guide tip to the resin material. ${ }^{25}$

Others, showed 3D views of light beam profile from dental 1CUs, and concluded that the irradiance at the light guide tip end of a wide variety of LCUs was not radically symmetrical and could be quiet inhomogenous. ${ }^{26}$

For light cure and dual cure cement polymerization, a certain quantity of luminous energy is necessary. ${ }^{27}$ Dental manufacturer defined $200 \mathrm{~mW} / \mathrm{cm}^{2}$ as minimal values. However, the values that were registered in the current study reveals low quantities of luminous energy at all levels of the root canal investigated. Previous studies showed low values of hardness and degree of conversion for resin cements; this fact was attributed to insufficient transmission of light at increased depths as was confirmed by the results of the current study.

High power blue LED curing devices are known for their curing potential. Although LED devices were to some extent inferior to high power QTH curing devices, current blue LED visible light curing units are comparable or even superior to high power QTH curing devices, due to an enormous increase of power output. The current study in comparing the light intensity between QTH, conventional LED and high power LED resulted in a significant difference between the three devices at the experimental and control groups. 
Nowadays, translucent fiber posts in conjunction with dual cured resin cement are preferred. The rationale of using dual cured resin cement is to have a material with extended working time, which is capable of polymerization by both chemical and light activation. However, many studies have proved that auto-polymerizing alone does not provide the adequate degree of conversion for the dual cure resin cement. ${ }^{20}$

Comparing the light intensity of the three devices at different levels revealed a significant difference, indicating that the light intensity depending on diameter of the translucent post that allow the light through to the material to be polymerized regardless the type of light curing units. This result may be explained, however, light intensity declines rapidly as the distance from the light source increases, because of light scattering within the resin cement and shadowing produced by both the tooth structure and post. Therefore, light intensity may be insufficient for the complete curing of resin cement at the apical end, which might lead to inferior physical and biological properties; this is confirmed by Ferrari ${ }^{21}$ who reported that the dual-cure self-activating system showed a more uniform resin tag and resin-dentin inter-diffusion zone formation along root canal walls than lightcuring systems.

The dentin substrate as well as its interaction with the adhesive systems with regards to the adhesion of the post and the cement through the composition, design, physical properties of the posts, and the use of silane.22 These two interfaces depend directly on the polymerization of the resin cements, which itself depends on the light transmission through the post a feature that is not fully understood ${ }^{26}$. Therefore, the inability of the apparatus to measure transmitted energy with a sensitivity of nano-watts was not relevant to our conclusions. The absorption and reflection of light, in the resin matrix, depends directly on the size and concentration of the filler and on the pigment color. ${ }^{27}$
Consequently, the differences in the chemical and structural composition of the posts are aspects that seem to explain the different light transmission values that were observed between them. The principle by which light that is irradiated on the post is dissipated and distributed in different directions is called absorbance and refraction. The quantity of light that will be absorbed, reflected, and transmitted seems to depend on the resin matrix and on the fiber composition of each post.

This absorption and dispersion of light in resinous materials reduces the energy density in an exponential form with a negative exponent as the penetration depth increases. Refraction favors the polymerization of cements that are situated radials, which seems to have great importance in the retention of a post. So, our study analyzed the light transmitted at the three levels (apical, middle and cervical) of the control groups, revealed a significance difference in the light intensity ,this indicate that the distance between the source of light and received polymerized surface and the diameter of the light that directed to the surface are the more effective factors.

To adequately polymerize a $2-\mathrm{mm}$ thick resin, $1,600 \mathrm{~mW} / \mathrm{cm}^{2}$ of energy is needed; consequently, a source that generates $400 \mathrm{~mW} / \mathrm{cm}^{2}$ is needed for 40 seconds. Considering a cementing layer of $50 \mathrm{~m}$ and the quantitative results of this work, the necessary activation time would be around 570 seconds for the apical third, 200 seconds for the middle third, and 90 seconds for the cervical third.

Nanometric quantities do not seem to have a significant influence on the polymerization of resin cement. ${ }^{28}$ This study had limitations in its ability to simulate root canal dentine. The root canal dentin may alter the current results.

Another limitation of this study was that the combined effects of the post diameter and/or longer application periods of light curing were not observed. The quantity of light transmitted through a fiber post is directly related to its diameter. ${ }^{24}$ 


\section{CONCLUSIONS}

\section{Within the limitations of the study, the following conclusions can be drawn:}

1. There was a significant reduction in the quantity of light transmitted through as the depth increased; regardless the source of the light.

2. Even without the post, the luminous intensity inside the canal decrease to levels insufficient for polymerization, especially in the apical third.

3. The light transmission capacity of the translucent posts, especially in the deeper regions, is insufficient for clinical luminous activation of resin.

4. It is preferred the use of the dual resin cement in cementation of intra-radicular post.

\section{REFERENCES}

1. Cook WD, Standish PM. Cure of resin based restorative materials: II. White light polymerized resins. Aus Dent J 1983;28:307-11.

2. Kanca J. The effect of thickness and shade on the polymerization of lightactivated posterior composite resin. Quintessence Int 1986;17:809-11.

3. Hofmann N, Hiltl O, Hugo B, Hlaiber B. Guidance of shrinkage vectors vs irradiation at reduced intensity for improving marginal seal of classVresin-based composite restorations in vitro. Oper Dent 2002;27:510-5.

4. Sakaguchi RL, Ferracane JL. Effect of light power density on development of elastic modulus of a model lightactivated composite during polymerization. J esthet Restor Dent 2001;13:121-30.

5. Yap AU, Seneviratne C. Influence of the light energy dentistry on effectiveness of composite cure. Oper Dent 2001;26:460-6.

6. Mills RW, Jandt KD, Ashworth SH. Dental composite depth of cure with halogen and blue light emitting diode technology. Br Dent J 1999;8:388-91.-6.

7. El-Mowafy O, El-Badrawy W, Lewis DW, Shokati B, Kermallii J, Sloiman ,et al. Intensity of quartz-tungstenhalogen-light-curing units used in private practices in Toronto. J Am Dent Assoc 2005;136:766-73.
8. Kleverlaan CJ, de Gee AJ. Curing efficiency and heat generation of various resin composites with high intensity halogen lights. Eur J Oral Sci 2004;112:84-8.

9. Lumileds Lighting. Thermal Design Using Luxeon Power Light Sources,Application Brief AB05. 2005.

10. Leonard DL, Charlton DG, Roberts HW, Cohen ME. Polymerization efficiency of LED curing lights. J Esthet Restor Dent 2002;14:286-95.

11. Asmussen E, Peutzfeldt A, Heitmann T. Stiffness, elastic limit, and strength of newer types of endodontics posts. J Dent 1999;27:275-8.

12. Peutzfeld A. Correlation between recordings obtained with a light intensity tester and degree of conversion of a lightcuring resin. Scand J Dent Res 1994;102:391-6.

13. Uhl A, Mills RW, Vowles RW, Jandt KD. Lnoop hardness depth profiles and compressive strength of selected dental composites polymerized with halogen and LED light curing technologies. J Biomed Mater Res 2002;63:729-38.

14. Lohbauer U, Rahiotis C, Kramer N, Petschelt A, Eliades $\mathrm{G}$. The of different light-curing units on fatigue behavior and degree of conversation of a resin composite. Dent Mater 2005;21:608-15.

15. Chan R, Bryant R. Post core foundation for endodontically treated posterior teeth. J Prosthodont 1982;48:401-5.

16. Newman MP, Yaman P, Dennison J, Rafter M, Billy E. Fracture resistance of endodontically treated teeth restored with composite posts. J Prosthet Dent 2003;89:360-7.

17. Fakiha Z, AL-Aujan A, AL-Shamarani S. Retention of cast posts cemented with zinc phosphate cement using different cementing techniques. J Prosthodont 2001;10:37-41.

18. TeixeiraFB,PiasickJR,ThompsonJY. An in vitro assessment of prefabricated fiber post systems. J Am Dent Assoc 2006;37:1006-12.6.

19. Musanje L, Darvell BW. Curing-light attenuation in filled resin restorative materials. Dent Mater J 2006;22:804-17.

20. Shorten AC, Harrington E, Wilson HJ. Light curing unit effectiveness assessed by dental radiometers. J Dent 1995;23:227-32.

21. Ferrari M, Vichi A, Grandini 5, Goracci C. Efficacy of a self-curing adhesive resin cement system on luting glassfiber posts into root canals: an SEM investigation. The Inter-national J Prosthodont 2001;14:543-9.

22. Chersoni S, Acquaviva GL, Prati C, et al. In vivo fluid movement though dentin adhesives in endodontically treated teeth. J Dent Res 2005;84:223-7. 
23. Taneja S, Kumari M, and Gupta A.Evaluation of light transmission through different esthetic posts and its influence on the degree of polymerization of a dual cure resin cement. J Conserv Dent. 2013 ; 16: 32-35.

24. Silva ALF, Arias VG, Soares LES, Martin AA, Martins LRM. Influence of fiber-post translucency on the degree of conversion of a dual-cured resin cement. J Endod 2007;33:303-5.

25. Rahiotis C, Patsouri2 KN), and Kakaboura, A. Curing efficiency of high-intensity light-emitting diode (LED devices J Oral Scin 2010; 52: 187-195.
26. Miyazaki M, Hattori T, Ichiishi Y, Kondo M, Onose H, Moore BK.Evaluation of curing units used in private dental offices. Oper Dent 1998;23:50-4.

27. Jacobi R, Shilingburg HT. Pins. dowels, and other retentive devices in posterior teeth. Dent Clin North Am 1993;37:367-90.

28. Luís Fernando A. M. LF, Peixoto RT,de Castro A.R, Santos MF, de Adreu LT, Pinotti MB. Light Transmission through a Translucent Fiber Post. J Endo 2008; 34:299-302. 